\title{
O PRAZER NAS MODALIDADES ESPORTIVAS DE COMBATE: A PULSÃO DE MORTE E A EXPERIÊNCIA DO ESPECTADOR
}

THE PLEASURE IN COMBAT SPORT MODALITIES: THE DEATH DRIVE AND THE SPECTATOR'S EXPERIENCE

\author{
EL PLACER EN LAS MODALIDADES DEPORTIVAS DE COMBATE: LA PULSIÓN DE MUERTE Y \\ LA EXPERIENCIA DEL ESPECTADOR
}

\author{
Guilherme Secotte \\ Gustavo Henrique Dionisio ${ }^{* *}$
}

\begin{abstract}
RESUMO
Este artigo analisa brevemente a história do combate esportivo, a fim de elucidar algumas características dos espetáculos das modalidades esportivas de combate na sociedade capitalista contemporânea, na medida em que a indústria cultural vende as competiçôes esportivas como mercadoria. Com esse viés, a reflexão se detém em um estudo preliminar sobre o prazer do espectador no ato de assistir aos espetáculos. Nessa perspectiva, propomos a concepção das lutas "estéticas", considerando-as como aquelas que podem proporcionar maior prazer aos espectadores. Para essa tarefa, utilizamos a teoria psicanalítica, sublinhando sobretudo a metapsicologia freudiana a respeito do prazer e da pulsão de morte para descrever que, por meio de mecanismos de identificação e projeção, o espectador pode expressar indiretamente sua agressividade ao assistir aos espetáculos das modalidades esportivas de combate.
\end{abstract}

Palavras-chave: Espectador. Modalidades esportivas de combate. Prazer. Psicanálise. Pulsão de morte.

\begin{abstract}
The present article makes a brief analysis of the history of combat sports in order to elucidate some of their main characteristics in the contemporary capitalist society, keeping in mind that the cultural industry deals with sport competitions as trading products. That said, the reflection focus on a preliminary study approaching the viewer's pleasure when watching the combat shows. Within this context, we propose the concept of "esthetic" fights, considering them as those that can provide the highest level of pleasure to the watcher. For this objective, we make use of the psychoanalytic theory, highlighting the Freudian metapsychology taking into consideration the
\end{abstract}

Texto recebido em 11 de abril de 2016 e aprovado para publicação em 23 de setembro de 2016.

* Graduando em Psicologia na Universidade Estadual Paulista (Unesp). E-mail: secotte@outlook.com.

"* Professor no Departamento de Psicologia Clínica da Unesp, psicanalista. E-mail: gustavohdionisio@gmail.com. 
pleasure and the death drive, to describe that through identification and projection mechanisms the spectators can indirectly express their aggression, while watching combat sports events.

Keywords: Viewer. Combat sports. Pleasure. Psychoanalysis. Death drive.

\section{RESUMEN}

Este artículo analiza brevemente la historia del combate deportivo, con la intención de aclarar algunas características de los espectáculos de las modalidades deportivas del combate en la sociedad capitalista contemporánea, en la medida en que la industria cultural vende las competiciones deportivas como una mercancía. En este sesgo, la reflexión se detiene al estudio preliminar sobre el placer del espectador en el acto de asistir a los espectáculos. De esa manera, proponemos la concepción de las luchas "estéticas", considerándolas como aquellas que pueden proporcionar mayor placer a los espectadores. Para esta tarea, utilizamos la teoría psicoanalítica, subrayando sobre todo la metapsicología freudiana que habla sobre el placer y la pulsión de muerte para describir que, por medio de mecanismos de identificación y proyección, el espectador puede expresar indirectamente su agresividad al asistir a los espectáculos de las modalidades deportivas del combate.

Palabras clave: Espectador. Modalidades deportivas del combate. Placer. Psicoanálisis. Pulsión de muerte.

\section{BREVE HISTÓRICO DO COMBATE ESPORTIVO}

Oomo se sabe, a cultura do espetáculo de combate não é um fenômeno
que surgiu recentemente, embora tenha ganhado extrema notoriedade
atualmente. Com efeito, as atividades que envolvem o confronto entre
lutadores fazem parte da longa história do homem, e isso implica que foi se
transformando no decorrer do tempo. Podemos notar, por exemplo, que, nos
costumes de antigas civilizaçôes, já estavam presentes atividades físicas que
poderíamos chamar de "pré-esportivas", e que, entre outras, estavam relacionadas
à guerra e à caça como uma espécie de "metáfora" de tais atividades, decorrendo na
criação de práticas como a luta corporal, esgrima, corrida ou mesmo caminhada,
conforme atesta Tubino (2010).
Ainda segundo o autor, o esporte (no sentido mais amplo do termo) divide-se
em três períodos históricos: Antigo, Moderno e Contemporâneo. As primeiras
manifestaçôes esportivas teriam ocorrido no chamado Período do Esporte Antigo, 
mais especificamente nos Jogos Gregos, com destaque para as Olimpíadas. Como sugere Godoy (1996), as primeiras atividades que carregaram um tom de "espetáculo de combate" teriam sido o pugilato, a luta grega e o pancrácio, todos os três esportes de ataque e defesa que proporcionavam grande prestígio aos competidores. A brutalidade dessas competições esportivas podia levar a graves lesóes ou mesmo à morte dos praticantes. O "pancrácio", certamente a modalidade mais agressiva, misturava a luta grega e o pugilato, no qual se permitia quase tudo, exceto furar os olhos, morder ou arranhar.

Esse conceito grego de esporte sofreu modificaçóes ao ser transportado para a Roma Antiga, passando então a ser reconhecido como "jogos públicos circenses", com notoriedade para os confrontos entre gladiadores. Nas arenas, como o Coliseu, os lutadores (que normalmente eram escravos e prisioneiros de guerra) trajavam armaduras e manejavam diversos tipos de armas em batalhas realmente mortais, muito apreciadas pelo grande público.

A Idade Média e a Renascença, por outro lado, demonstraram uma diminuição das práticas esportivas de combate. Contudo, ainda que escassas, continuaram costumeiramente violentas e, algumas vezes, mortais, como é o exemplo da Justa e dos Torneios Medievais. Essas duas modalidades atendiam não apenas às funções de divertimento, propiciando grandes espetáculos com a utilização de armas e armaduras, mas também às de treinamento militar.

Dando um salto considerável na linha cronológica que desenvolvemos até aqui, chegamos finalmente ao conceito de esporte conhecido hoje e que teve início na Inglaterra do século XIX, mais precisamente com Thomas Arnold, em 1820, ou seja: a noção de esporte com a qual lidamos diariamente nasceu concomitantemente com o processo da Revolução Industrial (Tubino, 2010). Regulado por regras mais explícitas e pelo máximo respeito a elas, a dinâmica dos jogos tendia a se tornar mais justa e equilibrada, culminando progressivamente em uma perda no nível de violência das modalidades esportivas de combate. Nesse contexto histórico, o nascimento do esporte moderno acompanha conjunturas políticas, sociais e econômicas do modo capitalista de produção, fatores que influenciaram e ainda influenciam a prática esportiva nos dias de hoje (Rubio, 2002).

Ainda na primeira metade do século XX, Adorno (2009) já analisava esse processo de capitalização da cultura que permanece atualmente conforme a lógica de uma "indústria cultural", isto é, uma máquina que "pode se vangloriar de haver atuado com energia e de ter erigido em princípio a transposição (tantas vezes grosseira) da arte para a esfera do consumo" (Adorno, 2009, p. 17), o que nos permite aprofundar a problemática recortada neste artigo, uma vez que é 
justamente a indústria cultural quem vende e distribui, como uma mercadoria entre outras, as competições esportivas.

Com o fim da Guerra Fria e com o fortalecimento da globalização, o processo de transição do esporte moderno para o contemporâneo se concatenaria quando o esporte, que era "pautado principalmente pela disputa político-ideológica, rumou no sentido da disputa mercadológica entre marcas e fornecedores, que financiam o espetáculo e direcionam o sentido das disputas" (Marques, Gutierrez, \& Almeida, 2007, p. 3, grifos nossos). Nesse mesmo sentido, e ainda de acordo com Tubino (2010), é mais precisamente no fim da década de 1980, sublinhando-se como marco a elaboração da Carta Internacional de Educação Física e Esporte, que se iniciaria o chamado esporte contemporâneo.

Dessa forma, e tendo em vista a atividade de combate como um fenômeno característico do esporte contemporâneo, Correia e Franchini (2010) nos auxiliam a designar o conjunto de lutas, artes marciais e sistemas de combate reunidos em apenas uma noção: "Modalidades Esportivas de Combate" (MEC). Ademais, as MEC enquadram-se na proposta de definição de esporte de autores como Barbanti (2006), para quem o esporte, no momento presente, é "uma atividade competitiva institucionalizada que envolve esforço físico vigoroso ou o uso de habilidades motoras relativamente complexas por indivíduos cuja participação é motivada por uma combinação de fatores intrínsecos e extrínsecos” (p. 57).

Ora, se concordarmos com o que foi exposto até o momento, é preciso reconhecer que, em nossa sociedade contemporânea, a competição esportiva profissional sofre forte influência do sistema capitalista de produção, e talvez como nunca o havia sofrido antes. Nessa perspectiva, o "Atleta profissional é um novo tipo de trabalhador que vende a um patrão sua força de trabalho (capaz de produzir um espetáculo que atrai multidões); é valor de troca de sua força de trabalho, regulado pelas leis de oferta e procura do mercado" (Rubio, 2002, p. 7).

Atualmente se sabe o quanto o esporte profissional é financiado principalmente por empresas que visam a divulgar uma marca e os produtos dela decorrentes, utilizando-se para isso a associação de seu produto aos atletas inseridos nas competiçôes esportivas profissionais. De forma semelhante, outro importante agenciador do espetáculo são os meios de comunicação de massa: redes de televisão, revistas esportivas, páginas de internet, campanhas publicitárias e mesmo o cinema patrocinam cada vez mais o esporte, com o intuito de vender mercadorias em seu sentido mais amplo: imagens, entretenimento, notícias também fazem parte do rol de vendáveis disponibilizados pela indústria cultural. 
Por fim, é preciso levar em consideração que o Estado também participa desse fenômeno, direta ou indiretamente, oferecendo subsídios que promovem o esporte ou, a título de exemplo, criando políticas que privilegiam certas práticas esportivas (em detrimento de outras, vale destacar). No Brasil, segundo o artigo 217 da Constituição de 1988, o Estado tem como dever oferecer recursos públicos tanto para o esporte educacional quanto para o de alto rendimento, de modo a fomentar práticas esportivas formais e não formais e, dessa forma, incentivar espetáculos esportivos (que também comportam capital da iniciativa privada). Como se sabe, a mão do Estado pesa fortemente em competiçôes como os Jogos Olímpicos, as Copas do Mundo de Futebol, etc.

\section{OS ESPETÁCULOS DAS MODALIDADES ESPORTIVAS DE COMBATE}

As MEC, assim como também ocorre em outras modalidades esportivas, têm um funcionamento de competitividade que é muito particular na sociedade capitalista atual: "Nessa condição, a vitória, e não a participação", escreve Rubio (2006, p. 87), "é o valor supremo da competição esportiva, isso porque à vitória estão associados o reconhecimento social, o dinheiro e o desejo da permanência levando ao menosprezo de qualquer outro resultado".

Podemos perceber o funcionamento desse sistema do esporte contemporâneo profissional com o exemplo do Ultimate Fighting Championship (UFC), um dos maiores campeonatos entre as MEC e que tem grande destaque na mídia atualmente. O UFC é um dos principais divulgadores das artes marciais mistas ou do Mixed Martial Arts (MMA), como ficou popularmente conhecido. Para se ter uma ideia de seu alcance, segundo Awi (2012), o UFC produz cerca de 30 eventos ao vivo por ano, chegando a 600 milhões de lares em 145 países e em 22 idiomas. E como faz questão de frisar o autor, em 2009, a revista Forbes estimou o valor da marca em U\$ 1,3 bilhão! A permanência do lutador nesse campeonato, sobretudo em razão desses números, depende da expectativa gerada pelo público e do desempenho vitorioso nos combates, isto é, trata-se de uma performance lucrativa por parte do atleta que, de certo modo, reproduz a competitividade do mercado de trabalho, tão presente no modo capitalista de produção (como não haveria de ser diferente).

Awi (2012) acrescenta que o "Maior trunfo do MMA está concentrado no que ele tem de mais simples. É o esporte que mais se aproxima de uma briga real. Dois caras dentro de uma jaula, sem armas, com o mínimo de equipamentos" (Awi, 2012, p. 21). Contudo esse imaginário de uma "briga real" não se realiza: os espetáculos promovidos pelos lutadores profissionais (do MMA e de outras 
MEC) são institucionalizados, os atletas são condicionados a vencer, implicando em treino e preparo intenso para as lutas. Cabe ao lutador profissional desenvolver sua técnica o mais aguçadamente possível, a ela aliada um forte condicionamento físico, assim como um preparo psicológico e estratégico bastante rigoroso, ou seja: elementos que "escapam" ao olho nu dos espectadores, seja presencialmente ou por meio da transmissão midiática, e que justamente distanciariam o combate da ideia de uma "briga real".

Nessa perspectiva, é preciso sublinhar que, quando a prática esportiva é exibida ao público e se torna assim um espetáculo, o esporte torna-se também mercadoria, como já dissemos. Ainda que de forma indireta, o espectador comum, aquele que se interessa pelos espetáculos, acompanha as notícias por meio dos veículos de comunicação, compra produtos esportivos ou de marcas que patrocinam o esporte e pratica alguma modalidade esportiva. $\mathrm{O}$ espectador acaba se tornando o grande financiador do atleta profissional e do staff que trabalha com ele. Dessa maneira, temos uma estrutura de funcionamento do espetáculo que depende diretamente da existência de um destinatário, que, de alguma forma, "financie" o esporte profissional.

Ora, diferentemente das práticas de cunho amador, o esporte profissional depende da presença sine qua non do espectador para que o trabalho dos profissionais possa ser remunerado. E é esse capital derivado do espetáculo que oferece a oportunidade de os atletas profissionais se dedicarem integralmente à atividade esportiva, podendo elevar o nível de seu desempenho nas competições. Mal comparando, o espectador se torna o grande responsável pela realização do espetáculo esportivo profissional; em certa medida, assim como Duchamp atestara a presença do espectador de arte como o grande realizador da obra (Frayze-Pereira, 1994).

Mas, afinal, o que os espetáculos das MEC poderiam oferecer "psicologicamente" aos espectadores? Como atração principal, os espetáculos proporcionam para o público o combate esportivo entre os lutadores, o que ocorre com os atletas trocando agressões físicas instituídas por regras com outros lutadores, tendo como finalidade nocauteá-los, rendê-los ou alcançar uma maior pontuação para vencer a luta. Em segundo plano, os espetáculos oferecem também o conjunto de elementos que contextualiza e promove os combates propriamente ditos; podemos citar, por exemplo, levando-se em consideração principalmente as competições esportivas de maior projeção, a exibição do preparo dos atletas para o combate, as entrevistas concedidas no backstage, a expectativa gerada pela publicidade na divulgação do evento, a infraestrutura que potencializa sua exibição, comentaristas, narradores, músicas e outros elementos que engrandecem esse já enorme cenário. 
Seguindo esta linha de raciocínio, questionamos: em termos psíquicos, o que levaria os espectadores das MEC a assistirem a esse tipo de espetáculo esportivo? Esboçamos algumas considerações, principalmente do campo psicanalítico, com a pretensão de compreender esse fenômeno que, nos dias hoje, atrai grande número de pessoas para seu mercado.

\section{O ESPECTADOR E A PSICANÁLISE}

Hans R. Jauss, um dos principais teóricos da Estética da Recepção, fazendo menção ao espectador de arte e aos leitores de obras literárias, afirma que o prazer estético "E um modo da experiência de si mesmo na capacidade de ser outro, capacidade a nós aberta pelo comportamento estético" (Jauss apud Dionisio, 2014 , p. 45). Com base nesse apontamento, podemos pensar que, no contexto do espetáculo das MEC, o que Jauss define como "comportamento estético" refere-se ao espetáculo em si, ou seja, à própria atividade exercida pelos lutadores no ato da execução da luta. Nesse sentido, o prazer da experiência estética das MEC relaciona-se com a possibilidade de o espectador colocar-se, de alguma forma, na função de "exercício" do lutador, colocar-se em seu lugar sem estar ali presente. E para que haja uma possível realização dessa função, afirma Dionisio (2010), na esteira de Freud, que "é necessário que o receptor se identifique com os heróis ou personagens em ação e, com isso, dê livre escoamento às suas próprias paixões através de um gozo com a narrativa" (p. 60).

No caso das MEC, partimos da hipótese de que o espectador deve "identificarse”, ao fim e ao cabo, com os lutadores:

O prazer estético é garantido por uma distância que permite fruir a obra sem sujar as mãos. De acordo com a teoria, a experiência com a arte é determinada pelo movimento destas identificações somadas a projeção e introjeção. A identificação, que seria a operação que ocorre primeiro, consiste na forma original com que o sujeito estabelece um laço afetivo com o objeto; em seguida, ela dará lugar a uma vinculação libidinal que adentra o espaço psíquico disponível ao ego - eis a introjeção. A projeção, por sua vez, seria o movimento contrário a essa internalização, e assim exterioriza o que foi introjetado (Dionisio, 2010, p. 49).

Esse processo de identificação pode transformar o mero espectador desinteressado em um verdadeiro torcedor, isto é, faz com que esse sujeito participe mais ativamente na realização do espetáculo esportivo, escolhendo, inclusive, uma das partes. A partir disso, esse tipo de espectador pode se identificar com alguns semelhantes que vivem a mesma experiência, a ponto de formarem um coletivo (eis a torcida) que, com sua força mais ou menos contagiante, funciona como 
uma espécie de aditivo ao espetáculo esportivo. Conforme observa Magnane (1969), não é raro que a emoção cresça significativamente em intensidade, em proporção ao número de espectadores.

Aproveitando a ocasião de um dos espetáculos do UFC produzidos no Brasil, mais precisamente o "UFC 134 - Silva vs. Okami", por exemplo, um torcedor espontaneamente filmou e publicou na internet trechos do comportamento da torcida durante o evento. Com esse vídeo de 2011, intitulado "Torcida do UFC Rio - The best crowd in the UFC History" ("Torcida", 2011) e publicado pelo canal "MMAAnimal.com" no Youtube, torna-se possível notar mais claramente o quanto os ídolos são ovacionados enquanto se apresentam para o combate; de mesmo modo, durante as lutas, conseguimos verificar em que medida o esforço dos atletas vai sendo incentivado pelo público. Em entrevistas e relatos midiáticos, é notável o número de atletas que consideram o torcedor uma "peça fundamental" em seu desempenho nas competições. Na entrevista coletiva após o evento citado, Maurício Rua, um dos lutadores, relata:

Quando a gente chega num certo ponto da carreira, a gente tira motivaçôes de vários lugares [ . . ], mas, com certeza, minha maior motivação são os meus fãs. São meus fâs que me dão gasolina, o combustível para todos os dias treinar duro e aguentar os treinamentos (UFC, 2011).

Nessa perspectiva, Magnane (1969) complementa: "Os esportistas reconhecem todos que um 'bom público' os ajuda a se superarem, enquanto que um público frio os incomoda" (1969, p. 85). Com isso podemos compreender mais de perto o quanto uma torcida pode interferir na produção e no resultado da competição esportiva nesse contexto das MEC.

E mesmo que o espectador não esteja presente no local onde ocorre o espetáculo, ele pode, com o auxílio da tecnologia atual, acompanhar vividamente o show sem grandes perdas, dado o grande investimento na qualidade das transmissões do show business contemporâneo.

Dessa forma, podemos afirmar que é estratégico para os organizadores das competiçôes mais populares das MEC criar "deliberadamente" um estímulo para que os espectadores se identifiquem com os lutadores. Ocorre que tais espetáculos, financiados pela indústria cultural, expõem a modalidade e o lutador conforme vão criando uma imagem da luta como a metáfora perfeita de um lugar de batalha, instigando a competitividade, a rivalidade, o revanchismo e o "sabor da vitória"; quer dizer, fatores esses altamente estimulados no dia a dia do mercado capitalista e dos quais dificilmente o sujeito poderá escapar se quiser nele sobreviver. 
Suplementando esse processo de identificação, a mídia brasileira também faz questão de trazer a público a história de vida dos atletas: lutadores como Anderson Silva, José Aldo e Acelino "Popó" Freitas, a título de exemplo, ganham ainda maior destaque quando os espectadores passam a conhecer sua classe social de origem, que, em geral, é claramente desprovida de recursos financeiros. Fomentando os espectadores com a construção de uma imagem de "atleta herói" (Amaro, 2014; Helal, Cabo, \& Marques, 2009), tais sujeitos se tornam objetos de construção de um modelo de subjetivação muito bem adaptado ao capitalismo contemporâneo. Divulgados como símbolos da superação, no qual o esforço individual se transforma magicamente em "chave para o sucesso", tanto atletas quanto espectadores são capturados por um discurso ilusório de que haveria a todos possibilidades iguais de ascensão social dentro do sistema.

Essa construção ideológica se dá de tal modo que os espectadores acabam sendo motivados a adotar um espírito claramente nacionalista. Assim o lutador nacional, tornado "objeto de identificação", é levado a obturar uma função vazia do eu que, por sua vez, representa uma certa imagem (narcísica) do desejo do espectador; já o lutador estrangeiro configura-se como um outro antagônico, isto é, aquele que é desconhecido, rival e adversário a ser vencido. Conforme pensa Žižek (2009), poderíamos questionar, nesse sentido, o que motivaria, em termos mais especificamente "ideológicos", o espectador das MEC: numa primeira visada, temos que a "indústria cultural" oferta mercadorias a serem consumidas, assim como cria as demandas de consumo conforme o modo operante do capital; em segundo lugar, o espetáculo evidencia imperativos culturais que são dependentes da recepção "local", isto é, nacional, do espectador. A combinatória dos fatos pode alienar o sujeito de maneira "compulsiva", por assim dizer, ao reforçar nele aspectos subjetivos cunhados por uma certa ideologia. Desse modo, concluímos com Žižek (2009) que a operação em jogo se direciona da ideologia para o inconsciente e vice-versa, isto é, dialeticamente, fazendo então bascular desejos e fantasias de um lado "e" indústria cultural de outro.

No UFC, nosso recorte de estudo aqui, é conhecida a estratégia de colocar os lutadores para se "enfrentar" (encarando-se) de antemão, isto é, antes mesmo do combate propriamente dito. Além disso, por meio de entrevistas, vídeos, mensagens pessoais publicadas na internet e de pesagens oficiais, é comum os lutadores se provocarem e, em alguns casos, chegarem a se insultar ou ainda a trocar agressões físicas (ou fingem que o estão fazendo), confirmando, assim, o estímulo da indústria cultural em promover no espectador a escolha de um dos lados antes mesmo do combate propriamente dito.

Dessa maneira, a realização das competições esportivas permite que conheçamos os campeões, mas é principalmente a mídia que, por meio de um largo e pensado 
processo de sugestão psicológica, permite que construamos nossas ilusões quanto aos ídolos e heróis na arena. Produzindo uma analogia relevante a esse respeito, Magnane (1969) compara os campeões esportivos com os astros de cinema: "A sedução que exercem sobre a multidão tem as mesmas causas: necessidade de um herói que triunfe sobre as dificuldades que nós próprios sofremos, e com quem a identificação seja possível, mesmo fácil” (Magnane, 1969, p. 99).

Nesse mesmo sentido, Dias e Sousa (2012) complementam, por meio de uma compreensão mais psicanalítica:

Façamos um paralelo com o que se dá no laço social em relação à figura do atleta. Esse sujeito, capaz de feitos impensáveis para um "simples mortal", acaba por ser admirado e valorizado e, do ponto de vista imaginário, cumpre essa função de um ideal. Somos falhos, castrados, mas essa figura de vencedor faz sonharmos com a possibilidade de um ideal de perfeição e onipotência, outrora imaginariamente vivido (p. 732).

Nessas condições, a publicidade tenta conciliar a imagem do atleta-herói com o produto anunciado, assim proporcionando uma falsa necessidade de consumo decorrente da ação manipulativa e, dessa forma, aliena os consumidores (Diniz \& Caleiro, 2012). Esse processo atende obviamente aos objetivos do marketing esportivo, auxiliando na promoção das modalidades, competiçôes e lutadores. "Observa-se com isso que a mídia e o esporte possuem na sociedade atual uma relação de interdependência em que o primeiro é transformado pelo segundo em espetáculo e mercadoria - fundamentado na Indústria Cultural" (Diniz \& Caleiro, 2012, p. 12), o que gera mais lucro aos veículos de comunicação e às empresas associadas à venda dos produtos esportivos.

Dentro dessa lógica que permeia o espetáculo, o prazer catártico faz função de atrativo, facilitando o processo de identificação do espectador com os modelos heroicos expostos pela indústria do entretenimento. Desse modo, o gozo (que não cessa) possibilitado pelo espetáculo e pela repetição maciça de conteúdos da "indústria cultural" permite a manutenção de um retorno em circuito que mantém o espectador "passivo-ativo"; seriam eles mortos-vivos contemporâneos, como problematiza Arreguy (2015, p. 100). Ou seja, o espectador então "goza", conforme propõe Lacan, no sentido ambíguo próprio a essa acepção: por um lado, é passivo porque não está atuando dentro da cena; por outro, é ativo, já que implicado num gozo outro que o excita e, justamente por isso, faz com que retome um retorno em circuito para, com ele, aproveitar os benefícios secundários da situação.

Entretanto se transportarmos a afirmação de Jauss sobre a arte para o campo do espetáculo esportivo, é possível entender que a sugestão produzida pela indústria cultural teria um poder decerto "limitado" sobre o espectador. 
É só de modo parcial que a necessidade estética é manipulável, pois a produção e a reprodução da arte, mesmo sob as condições da sociedade industrial, não consegue determinar a recepção: a recepção da arte não é apenas um consumo passivo, mas sim uma atividade estética, pendente da aprovação e da recusa, e, por isso, em grande parte não sujeita ao planejamento mercadológico (Jauss apud Dionisio, 2010, p. 61).

Oespectador, mesmoquandoassumeumaposiçãopassiva, participadiretamente na recepção dos espetáculos das MEC, pois o processo de identificação tem um funcionamento inseparável com o de projeção. Laplanche e Pontalis (2001) definem a projeção, de modo clássico, como uma "operação pela qual o sujeito expulsa de si e localiza no outro - pessoa ou coisa - qualidades, sentimentos, desejos e mesmo 'objetos' que ele desconhece ou recusa nele" (Laplanche, \& Pontalis, 2001, p. 374). Nesse sentido, o sujeito pode identificar-se com o outro por elementos que pertencem a ele mesmo, ou seja, atribui conteúdos próprios a esse outro e os reconhece como se não fossem seus. $O$ prazer propiciado pelo espetáculo de combate pode, então, ter auxílio do próprio psiquismo do espectador que, por meio da projeção, encontra conteúdos do sujeito expressos na produção do espetáculo das MEC, os quais retornam a ele como um aditivo, um mais de gozar em sua experiência vivida enquanto espectador. Assim o espetáculo "rouba da plateia um a mais de gozo, ao imprimir um ritmo intenso, imediatista e frenético, para o regime das pulsões" (Arreguy, 2015, p. 101; Lacan, 1972-1973/1985'). Por meio da identificação e da projeção, a experiência do espectador das MEC permite que ele sinta o prazer indireto da luta sem efetivamente exercer a atividade, assegurando-o da agressão do adversário e do desgaste físico do combate, entre outras experiências desagradáveis, por assim dizer. É como se ele atualizasse a teoria freudiana a respeito da experiência do sujeito com a obra de arte: ele pode gozar do acontecido sem sujar as mãos, ou seja, extrair uma experiência "afetiva" (e mais ou menos repleta de intensidades) do combate esportivo sem precisar lutar.

Além disso, supomos que o espectador deseja ver lutas "estéticas", isto é, que o nível técnico dos competidores seja expresso da forma mais "bela e admirável" possível nos espetáculos das MEC. Nessa acepção, os melhores combates seriam aqueles que apresentam movimentos harmônicos, bem executados, evidenciando a técnica aguçada do lutador profissional. No esporte, geralmente, esses movimentos ou golpes mais "plásticos" são aqueles que a indústria do entretenimento utiliza em especial ao longo dos replays, no material principal para a promoção dos eventos e na seleção dos melhores momentos das lutas. Com efeito, no cinema, é comum vermos idealizada essa beleza do combate filmes como Rocky, um lutador (1977) ou Karatê Kid: a hora da verdade (1984) -

1 A primeira data indica o ano de publicação da obra, e a segunda, a edição consultada pelo autor, a qual somente será pontuada na primeira citação da obra no texto. Nas seguintes, será registrada apenas a data de publicação original. 
ambos de John G. Avildsen, para ficar apenas nos hollywoodianos mais famosos, são exemplos incontestes. Consideramos como um movimento "estético", por exemplo, um chute (que é utilizado em diversas modalidades) no qual o atleta gira em seu próprio eixo e atinge a cabeça do adversário com o calcanhar. Esse golpe, além de ser de difícil execução, apresenta alta potência, podendo levar o adversário a nocaute, quando então chegamos ao clímax da luta; clímax naturalmente produtor de uma descarga psíquica que se dá pela via da catarse. Dessa maneira, quando os atletas realizam uma luta com essas características, supomos que há maior possibilidade de os espectadores terem uma experiência prazerosa ao assistir ao espetáculo.

Considerando que o espectador se identifica com o lutador e projeta conteúdos próprios nele (colocando-se simbolicamente em seu papel), aventamos a hipótese de que essa experiência seria motivada por um "prazer específico" que leva o espectador a assistir aos espetáculos de MEC, hipótese à qual nos dedicaremos, ainda que muito parcialmente, em seguida, no momento de concluir.

\section{FREUD E O PRAZER}

De acordo com Freud (1920a/2006), o prazer corresponde à diminuição da quantidade de excitação no "aparelho psíquico", na mesma medida em que o desprazer ao aumento da excitação. Prazer e desprazer operam, portanto, segundo as regras do "princípio de prazer", resumidamente como "uma tendência que opera a serviço de uma função, cuja missão é libertar inteiramente o aparelho mental de excitações, conservar a quantidade de excitação constante nele, ou mantê-la tão baixa quanto possível" (Freud, 1920a, p. 73).

Seguindo essa linha de raciocínio, para diminuir a quantidade de excitação, o sujeito deve encontrar meios para satisfazer as pulsóes. Elas, por sua vez, são representantes psíquicos "dos estímulos que se originam dentro do organismo e alcançam a mente, como uma medida da exigência feita à mente no sentido de trabalhar em consequência de sua ligação com o corpo" (Freud, 1915/1996, p. 142), ganhando representação na vida psíquica no momento em que exercerem pressão. Sua finalidade, como se sabe, é a satisfação, ou seja, a eliminação do estado de estimulação em sua fonte, e, para tanto, é pela via dos objetos (sendo esses os mais variáveis dentro da equação pulsional) que elas poderão atingir essa finalidade (Freud, 1915). Em Além do princípio de prazer, uma de suas obras mais maduras, Freud (1920b/2010) vai "além", revelando um tipo de pulsão que teria um funcionamento particular. Retomando a afirmação de que o princípio de prazer tem como missão libertar inteiramente o aparelho mental de excitações, seria, portanto, função da "pulsão de morte" recorrer, aliado à tendência de 
compulsão à repetição, a um estágio anterior à vida no qual os seres ainda não sofreriam excitações internas.

Vista sob essa luz, diminui consideravelmente a importância teórica dos instintos de autoconservação, de poder e de autoafirmação; são instintos parciais, destinados a garantir o curso da morte própria do organismo e manter afastadas as possibilidades de retorno ao inorgânico que não sejam imanentes (Freud, 1920b, p. 150). ${ }^{2}$

Retomando a temática das MEC, entendemos que a atividade do lutador no combate tem como princípio a agressividade. Como vimos, é por meio desse princípio que o atleta conseguirá vencer a luta. No que tange à teoria psicanalítica, a agressividade não é outra coisa senão uma forma de expressão da pulsão de morte.

A tese sobre a pulsão de morte diz que a agressividade está presente desde o início da vida humana: a princípio, como autodestruição [. . .], depois, como agressão dirigida ao mundo externo [. . .]. Assim, a direção da agressividade para o exterior é uma proteção para o organismo, pois se permanecesse somente interno, o impulso de morte destruiria o indivíduo (Lourenço, 2004, p. 72).

Assim, compreendemos que haveria uma força no aparelho mental que exige do sujeito a criação de certos canais para a expressão da agressividade, isto é, ferramentas que possam auxiliar na resposta à exigência de que a pulsão venha a atingir sua finalidade (lembremos, a satisfação). Nesse sentido, podemos refletir que a pulsão de morte (Todestrieb), por meio da manifestação agressiva e atuando em sincronia com as pulsões de vida, forneceria ao atleta, por intermédio do trabalho do eu, a energia pulsional necessária para que ele consiga lutar, ou mesmo resistir; ainda que a pulsão de morte, tal como qualquer outra pulsão, exerça uma pressão para atingir sua finalidade, nos mais variados meios em que pode atuar. Conforme aponta Ferrari (2006), a agressividade "pode ser sublimada, pode ser recalcada, não precisa ser atuada, pois o humano conta com o recurso da palavra, da mediação simbólica” (pp. 51-52). Dessa forma, ela pode se reconfigurar e ser observada nas relaçôes sexuais, nos contatos sociais, nas artes, nos esportes, nos jogos e em outras atividades culturais. Entretanto, quando a pulsão de morte não encontra saída para se manifestar por atividades como essas, ela pode vir a se expressar na forma de violência, ou seja, em atos de violência ou destruição dirigida sobretudo ao outro (Costa, 1986).

Sob o ponto de vista sociológico e numa outra acepção sobre a violência e a agressividade, Elias e Dunning (1992) complementam:

\footnotetext{
2 É pena que essa versão mais recente do texto freudiano (Editora Companhia das Letras) tenha escolhido "instinto" em vez de "pulsão" para traduzir o termo Trieb. Optamos por seu uso mais em virtude de sua atualidade do que por sua acuidade terminológica.
} 
Todos os desportos são, por natureza, competitivos e conduzem, deste modo, ao aparecimento da agressão e de violência. Contudo, em alguns, por exemplo, o râguebi, o futebol, e o boxe, a violência é, sob a forma de "representação de uma luta" ou "confronto simulado" entre dois indivíduos ou grupos, um ingrediente central. Esses desportos constituem oportunidades para a expressão da violência física socialmente aceitável e ritualizada (Elias \& Dunning, 1992, p. 331).

Freud (1920a) afirmou, em Além do princípio de prazer, que as representações artísticas que se dirigem a uma audiência "não poupam aos espectadores (como na tragédia, por exemplo) as mais penosas experiências, e, no entanto, podem ser por eles sentidas como altamente prazerosas" (p. 28). Considerando essa afirmação no contexto do espetáculo das MEC, a pulsão de morte, que se expressa sob a forma de agressão nas lutas, poderia ser sentida como "desagradável" pelo espectador. Entretanto, "Mesmo sob a dominância do princípio de prazer, há maneiras e meios suficientes para tornar o que em si mesmo é desagradável num tema a ser rememorado e elaborado na mente" (Freud, 1920a, p. 28), possibilitando transformar essa experiência desagradável em seu contrário, ou melhor, em produtora de prazer. Um dos artifícios do aparelho mental que possibilita tal feito é propriamente a projeção, mecanismo que, além de trabalhar dialeticamente com a identificação do espectador com os lutadores, também pode, como afirma Freud, lidar com as "excitações internas que produzam um aumento demasiado grande de desprazer e tratá-las como se atuassem, não de dentro mas de fora" (eis a projeção), "de maneira que seja possível colocar o escudo contra estímulos em operação, como meio de defesa contra elas" (Freud, 1920 a, p. 40). Nesse sentido, a projeção atua como um mecanismo de defesa aos próprios desejos do sujeito, podendo colocar-se como um "escudo" diante da finalidade pulsional. Encontramos uma familiaridade entre as ideias de Elias e Dunning (1992) e a teoria psicanalítica a respeito desse processo de elaboração:

O desporto, tal como outras actividades de lazer, no seu quadro específico, pode evocar através dos seus desígnios, um tipo especial de tensão, um excitamento agradável e, assim, autorizar os sentimentos a fluírem mais livremente. Pode contribuir para perder, talvez para libertar, tensões provenientes do stress. O quadro do desporto, como o de muitas outras actividades de lazer, destina-se a movimentar, a estimular as emoções, a evocar tensões sob a forma de uma excitação controlada e bem equilibrada, sem riscos e tensões habitualmente relacionadas com o excitamento de outras situações da vida, uma excitação mimética que pode ser apreciada e que pode ter um efeito libertador, catártico, mesmo se a ressonância emocional ligada ao desígnio imaginário contiver, como habitualmente acontece, elementos de ansiedade, medo - ou desespero (Elias, \& Dunning, 1992, p. 79).

Nesse sentido, supomos que as MEC são um meio possível de os espectadores expressarem sua agressividade de maneira prazerosa sem que ela se torne 
violência, ou, sob outra concepção de violência, que ela seja socialmente aceita. Esse pensamento está de acordo com outros autores, como Prata (2000), que ressalta o trabalho criativo e produtivo derivado da pulsão de morte quando consoante com as pulsões de vida.

Para finalizar, sublinhamos que este ensaio foi uma tentativa de demonstrar em que medida o espectador pode se libertar, ainda que parcialmente, do recalcamento e assim "exprimir" fragmentariamente sua quota de pulsão de morte ao assistir aos combates, e, como resultado dessa experiência, extrair algum tipo de prazer (que não seria da ordem da dor) de sua aparelhagem psíquica. $\mathrm{O}$ prazer em jogo aqui se refere a um "mínimo de ligação" da pulsão de morte, a saber: de sua expressão pela via da destruição e agressividade (e não da morte propriamente dita), ainda que indiretamente vividas por meio dos espetáculos de combate. Entretanto ainda ressaltamos que essa problemática ilustraria igualmente um prazer proveniente de um gozo que não cessa, isto é, que se repete compulsivamente e que facilitaria então o consumismo alienado deste tipo de espetáculo. "A 'diversão' ou 'distração', como proposta por Adorno", considera Arreguy (2015, p. 105), "apresenta necessariamente uma estética ${ }^{3}$ de gozo que engaja o espectador na cena, não importa qual resultado possa tirar de seu lazer, que passa a ser um veículo de violência a ser passivamente usufruída". Ainda que feita em outro contexto, a questão da autora nos pode servir visto que os espectadores das MEC talvez sejam mesmo "passivos, desmotivados, alienados num tipo de cultura em que não têm capacidade de transformação, logo, agem como se fossem zumbis, sanguessugas, ou ainda, mortos-vivos, que se prestam a consumir e a gozar de imagens traumáticas de violência" (Arreguy, 2015, p. 100), sobretudo no que concerne à sua vontade de "diversão"; o que, em boa medida, excluiria do contexto a capacidade para a crítica.

Por fim, compreendemos que aspectos sociais, políticos e econômicos possibilitam entendermos o esporte como mercadoria, fator fundamental no processo de subjetivação do espectador contemporâneo das MEC. Com isso, consideramos que uma investigação de campo e uma maior exploração teórica acerca desta temática seria de grande relevância para auxiliar na compreensão psicológica desse fenômeno, tarefa que poderá ser objeto de novas análises.

3 A nosso ver, o uso do termo "estética" empregado pela autora mereceria um debate à parte, mas que não nos caberá discutir neste momento. 


\section{REFERÊNCIAS}

Adorno, T. W. (2009). Indústria cultural e sociedade. São Paulo: Paz e Terra.

Amaro, F. (2014). O Jornal do Brasil e a representação dos atletas brasileiros nos Jogos Olímpicos: notas de uma pesquisa. Estudos em Jornalismo e Mídia, 11(2), 472-483. Recuperado a partir de https://comunicacaoeesporte.files.wordpress. com/2010/10/idolatria-nos-jogos-pan-americanos-de-20071.pdf

Arreguy, M. E. (2015). Estéticas da diversão nos "mortos-vivos" contemporâneos. Psicologia USP, 26(1), 100-107. Recuperado a partir de https://dx.doi. org/10.1590/0103-656420130028

Awi, F. (2012). Filho teu não foge à luta: como os lutadores brasileiros transformaram o MMA em um fenômeno mundial. Rio de Janeiro: Intrínseca.

Barbanti, V. (2006). O que é esporte? Revista brasileira de atividade física \& saúde, 11(1), 54-58. Recuperado a partir de https://periodicos.ufpel.edu.br/ ojs2/index.php/RBAFS/article/view/833/840

Constituição da República Federativa do Brasil de 1988. (1988, 5 de outubro). Brasília. Recuperado a partir de http://www.planalto.gov.br/ccivil_03/ Constituicao/Constituicao.htm

Correia, W. R. \& Franchini, E. (2010). Produção acadêmica em lutas, artes marciais e esportes de combate. Motriz, 16(1), 67-81. Recuperado a partir de http://www.periodicos.rc.biblioteca.unesp.br/index.php/motriz/article/ view/2800/2707

Costa, J. F. (1986). Violência e psicanálise. Rio de Janeiro: Graal.

Dias, M. H. \& Sousa, E. L. A. (2012). Esporte de alto rendimento: reflexões psicanalíticas e utópicas. Psicologia \& Sociedade, 24(3), 729-738. Recuperado a partir de http://www.scielo.br/scielo.php?script=sci_arttext\&pid=S0102$71822012000300026 \& \operatorname{lng}=$ en $\&$ nrm $=$ iso

Diniz, I. G. F. \& Caleiro, M. M. (2012, junho). Esporte e mídia: uma interdependência de consumo. In Anais, 17 Congresso de Ciências da Comunicação na Região Sudeste, Ouro Preto. São Paulo: Sociedade Brasileira de Estudos Interdisciplinares da Comunicação.

Dionisio, G. H. (2010). Pede-se abrir os olhos: psicanálise e reflexão estética hoje. (Tese de Doutorado). Universidade de São Paulo. Instituto de Psicologia da 
Universidade de São Paulo, São Paulo.

Dionisio, G. H. (2014). Psicanálise e estética da recepção: desacordos e entrecruzamentos. Agora, 17(1), 43-58. Recuperado a partir de http://www. scielo.br/scielo.php?script=sci_arttext\&pid=S1516-14982014000100003\&ln $\mathrm{g}=\mathrm{en} \& \mathrm{nrm}=$ iso

Elias, N. \& Dunning, E. (1992). A busca da excitação. Lisboa: Difel.

Ferrari, I. F. (2006). Agressividade e violência. Psicologia Clínica, 18(2), 4962. Recuperado a partir de http://www.scielo.br/scielo.php?script=sci_ arttext\&pid=S0103-56652006000200005\&lng=en\&nrm=iso

Frayze-Pereira, J. A. (1994). A alteridade da Arte: estética e Psicologia. PsicologiaUSP, 5(1-2), 5-60.

Freud, S. (1915). Os instintos e suas vicissitudes. In J. Salomão (Trad.), Edição standard das obras psicológicas completas de Sigmund Freud (Vol. 14, pp. 129162). Rio de Janeiro: Imago, 1996. (Publicado originalmente em 1915).

Freud, S. (1920a). Além do princípio do prazer. In J. Salomão (Trad.), Edição standard brasileira das obras psicológicas completas de Sigmund Freud. (Vol. 18, pp. 13-85). Rio de Janeiro: Imago, 2006. (Publicado originalmente em 1920).

Freud, S. (1920b) Além do princípio do prazer. In Sigmund Freud: obras completas (Vol. 14, pp. 120-178). São Paulo: Companhia das Letras, 2010. (Publicado originalmente em 1920).

Godoy, L. (1996). Os Jogos Olimpicos na Grécia Antiga. São Paulo: Nova Alexandria.

Helal, R., Cabo, A., \& Marques, R. G. (2009). Idolatria nos Jogos PanAmericanos de 2007: uma análise do jornalismo esportivo. Contemporânea, 7(3), 33-44. Recuperado a partir de http://www.e-publicacoes.uerj.br/ojs/ index.php/contemporanea/article/view/309/533

Lacan, J. (1972-1973). Mais, ainda. In J. Lacan, J. A. Miller. O seminário: Livro 20. Rio de Janeiro: Jorge Zahar, 1985. (Publicado originalmente em 19721973).

Laplanche, J. \& Pontalis, J-B. (2001). Vocabulário da psicanálise. São Paulo: Martins Fontes. 
Lourenço, L. C. A. (2004). Reflexões sobre a violência e o homem contemporâneo. Psicologia: Ciência e Profissão, 24(1), 64-73. Recuperado a partir de http://www. scielo.br/scielo.php?script=sci_arttext\&pid=S1414-98932004000100008\&ln $\mathrm{g}=\mathrm{pt} \& \mathrm{nrm}=\mathrm{iso}$

Magnane, G. (1969). Sociologia do esporte. São Paulo: Perspectiva.

Marques, R. F. R, Gutierrez, G. L., \& Almeida, M. A. B. (2007). A transição do esporte moderno para o esporte contemporâneo: tendência de mercantilização a partir do final da Guerra Fria. In Anais do 1 Encontro da ALESDE "Esporte na América Latina: atualidade e perspectivas", UFPR, Curitiba. Curitiba: ALESDE-UFPR.

Prata, M. R. (2000). Pulsão de morte: mortificação ou combate? Ágora, 3(2), 115-135. Recuperado a partir de https://dx.doi.org/10.1590/S151614982000000200007

Rubio, K. (2002). O trabalho do atleta e a produção do espetáculo esportivo. Revista Electrónica de Geografía y Ciencias Sociales, 119(95)._Recuperado a partir de http://www.ub.edu/geocrit/sn/sn119-95.htm

Rubio, K. (2006). O imaginário da derrota no esporte contemporâneo. Psicologia \& Sociedade, 18(1), 86-91. Recuperado a partir de http://www.scielo.br/scielo. php?script=sci_arttext\&pid=S0102-71822006000100012\&lng=en\&nrm=iso

Torcida do UFC Rio: the best crowd in the UFC history (2011). [Youtube]. Recuperado a partir de https://www.youtube.com/watch?v=oIj46jPZ6Ng.

Tubino, M. J. G. (2010). Estudos brasileiros sobre o esporte: ênfase no esporteeducação. Maringá: Eduem.

Ultimate Fighting Championship. Coletiva de imprensa pós-UFC Rio. Rio de Janeiro: UFC, 2011. Recuperado a partir de http://www.ufc.com.br/media/ UFCRIO-POST-PC-ARCHIVE.

Žižek, S. (2009). Lacrimae rerum: ensaios sobre cinema moderno. São Paulo: Boitempo. 